\title{
SENSITIVITAS ETIS DAN PERTIMBANGAN ETIS MAHASISWA AKUNTANSI BERDASARKAN PENDIDIKAN ETIKA AKUNTANSI
}

\section{ETHICAL SENSITIVITY AND ETHICAL CONSIDERATIONS OF ACCOUNTING STUDENTS BASED ON ACCOUNTING ETHICS EDUCATION}

\author{
Anggi Ayu Septi Kennedy ${ }^{1}$ ), Lisa Martiah NP²) \\ Universitas Bengkulu, Jl. WR. Supratman,Kandang Limun, Muara Bangkahulu, Bengkulu \\ anggiayusepti@gmail.com ${ }^{1}$ ), lisa_mnp@unib.ac.id ${ }^{2}$ )
}

\begin{abstract}
This study examined the differences between ethical sensitivity and ethical judgement by students based on their knowledge of accounting ethics education. A total of 40 accounting students attended accounting ethics education in University of Bengkulu responded to questionnaire and another 43 students who does not complete an accounting ethics education were included for comparative purpose. Statistical analysis reveals that students who attended an accounting ethics education improved significantly in their ethical sensitivity and ability to made an ethical judgement compared to students who does not attended the accounting ethics education. Females students got more benefit from an accounting ethics education and increased their ability to made ethical judgement compared to male students, but in contrast, between male students and female students who attended accounting ethics education has no difference in terms of their ethical sensitivity.
\end{abstract}

Key words: Ethical sensitivity, ethical judgement, accounting ethics education

\begin{abstract}
ABSTRAK
Penelitian ini menguji perbedaan sensitivitas etis dan pertimbangan etis mahasiswa akuntansi berdasarkan pendidikan etika akuntansi. Sebanyak 40 mahasiswa akuntansi yang telah mengikuti pendidikan etika akuntansi terlibat dalam pengisian kuesioner dan sebanyak 43 mahasiswa yang belum mengikuti pendidikan etika akuntansi juga ikut untuk tujuan perbandingan. Analisis statistik mengungkapkan bahwa mahasiswa yang mengikuti pendidikan etika akuntansi meningkatkan sensitivitas etis dan kemampuan membuat pertimbangan etis dibandingkan mahasiswa yang belum mengikuti pendidikan etika akuntansi. Mahasiswa perempuan mendapatkan banyak manfaat dari pendidikan etika akuntansi dan menaikkan kemampuan membuat pertimbangan etis mereka, namun sebaliknya, antara mahasiswa laki-laki maupun mahasiswa perempuan yang telah mengikuti pendidikan etika tidak memiliki perbedaan dalam hal sensitivitas etis.
\end{abstract}

Kata Kunci : Sensitivitas Etis, Pertimbangan Etis, Pendidikan Etika Akuntansi

\section{PENDAHULUAN}

Beberapa penelitian telah dilakukan sebagai tanggapan terhadap keraguan pentingnya pendidikan etika bagi mahasiswa akuntansi. Beberapa penelitian menginvestigasi efektivitas intervensi program etika dengan membandingkan mahasiswa yang mengikuti pendidikan etika dengan mahasiswa yang tidak mendapatkan pendidikan etika (Abdolmohammadi \& Reeves ,2000; Armstrong M. B, 1993; Billiot, Daniel, Glandon, \& Glandon, 2012; Cabe, 2016; Chan \& Leung, 2006; Keller, et al., 2007; LaGrone, et al., 1996; Lau, 2010; Molyneaux, 2004; O'Leary, 2009; Taylor, 2013; Wang \& Calvano, 2015). 
Penelitian ini merupakan gabungan penelitian sebelumnya dari Saat et al. (2010a, 2010b) yang masing-msing hanya menguji satu komponen dari model Rest (1986) saja. Kali ini akan diuji sensitivitas etis dan pertimbangan etis mahasiswa akuntansi berdasarkan pendidikan etika akuntansi. Sebelumnya, dalam beberapa penelitian, pendidikan yang dimaksud merupakan program yang berdiri sendiri dan dimasukkan ke dalam kurikulum akuntansi. Namun, karena tidak adanya program pendidikan etika tersendiri yang dimasukkan dalam silabus akuntansi di Universitas Bengkulu, maka kali ini muatan etika yang terdapat dalam mata kuliah audit dan akuntansi keperilakuanlah yang akan diuji pengaruhnya terhadap sensitivitas etis dan penilaian etis mahasiswa akuntansi.

Berdasarkan latar belakang di atas, maka penelitian ini bertujuan untuk membuktikan bahwa kemampuan mahasiswa yang telah mengikuti pendidikan etika akuntansi lebih baik dalam mengidentifikasi dilema etika dibandingkan kemampuan mahasiswa yang belum mengikuti pendidikan etika akuntansi. Selanjutnya, penelitian ini juga membuktikan bahwa kemampuan mahasiswa perempuan yang telah mengikuti pendidikan etika akuntansi lebih baik dalam mengidentifikasi dilema etika dibandingkan dengan mahasiswa laki-laki, membuktikan bahwa kemampuan mahasiswa yang telah mengikuti pendidikan etika akuntansi lebih baik dalam membuat pertimbangan etis dibandingkan kemampuan mahasiswa yang belum mengikuti pendidikan etika akuntansi dan terakhir membuktikan bahwa kemampuan mahasiswa perempuan yang telah mengikuti pendidikan etika lebih baik dalam membuat pertimbangan etis dibandingkan dengan mahasiswa laki-laki

\section{KERANGKA TEORITIS DAN HIPOTESIS}

\section{Teori Penalaran Moral}

Etika atau moral reasoning berbeda dengan proses mental lainnya dalam tiga aspek yaitu kognisi yang didasarkan pada nilai dan bukan pada fakta yang nampak, keputusan yang didasarkan pada beberapa isu yang melibatkan diri sendiri dan orang lain, serta keputusan yang dibangun di seputar isi keharusan dan bukan pada peringkat preferensi atau kesukaan sederhana (Lubis, 2010). Mayoritas penelitian mengenai perilaku etis akuntansi pada studi akuntansi berlandaskan pada psikologi penalaran moral yang merupakan suatu teori kognitif tentang proses pengambilan keputusan manusia mendahului perilaku etis (Bennie \& Mladenovic, 2013).

\section{Sensitivitas Etis}

Sensitivitas etis mengacu pada kesadaran bagaimana tindakan seseorang mempengaruhi orang lain (Chan \& Leung, 2006). Menurut Saat et al. (2010b), sensitivitas etis merupakan pengidentifikasian sebuah situasi moral, mengambil peran, menafsirkan masalah dan menyadari bahwa ada masalah moral. Lebih lanjut, Jagger (2011) menyatakan bahwa sensitivitas etis adalah kemampuan untuk mengidentifikasi aspek yang menonjol dari dilema etika.

\section{Pertimbangan Etis}

Pertimbangan etis adalah konstruk psikologis yang mengkarakterisasikan proses bagaimana seseorang memutuskan bahwa serangkaian tindakan dalam situasi tertentu adalah benar secara moral dan serangkaian tindakan lain adalah salah (Shawver \& Shawver, 2013). Ini melibatkan kemampuan seseorang untuk memilih tindakan moral sehingga seseorang dapat 
menunjukkan kesadaran akan masalah (sensitivitas moral). Pertimbangan etis merupakan salah satu komponen lanjutan dari pembangunan kognitif yang dikembangkan oleh psikolog Lawrence Kohlberg dan wawancara pertimbangan moralnya dan selanjutnya dinilai dengan DIT.

\section{Pendidikan Etika Akuntansi}

Etika ialah studi tentang tindakan moral atau sistem atau kode berperilaku yang mengikutinya (Utami \& Indriawati, 2006). Menurut Agoes dan Ardana (2011) dalam Sapariyah et al. (2015) etika adalah cabang ilmu yang membahas tentang perilaku manusia, mengenai apa yang baik dan apa yang tidak baik dalam konteks hubungan manusia dengan Tuhan, manusia dengan manusia lain, dan manusia dengan alam.

\section{Jenis Kelamin}

Jenis kelamin merupakan suatu akibat dari dimorfisme seksual yang pada manusia dikenal menjadi laki-laki dan perempuan (wikipedia, 2016). Jenis kelamin dikaitkan pula dengan aspek gender, karena terjadi diferensiasi peran sosial yang dilekatkan pada masingmasing jenis kelamin.

\section{Pengembangan Hipotesis}

Hubungan antara pelajaran mengenai etika keprofesionalan dengan praktik di lapangan adalah ketika seorang mahasiswa S1 akuntansi tidak mendapatkan pelajaran etika yang memadai maka nantinya ketika terjun ke lapangan, keputusan yang diambil pasti tidak didasarkan pada kode etik yang seharusnya. Oleh karena itu pembelajaran etika sangat dibutuhkan untuk menghasilkan para profesional yang bisa membuat keputusan etis berdasarkan kode etik yang seharusnya. Sehingga nantinya para profesional di bidang akuntansi menjadi para profesional yang berkompeten dan bisa mengembalikan kredibilitas akuntansi di mata masyarakat.

Berdasarkan penjelasan diatas maka dirumuskan hipotesis berikut:

H1a: Kemampuan mahasiswa yang telah menerima pendidikan etika akuntansi lebih baik dalam mengidentifikasi dilema etika dibandingkan kemampuan mahasiswa yang belum mengikuti pendidikan etika akuntansi

Atribut yang paling sering diselidiki di penelitian tentang pandangan etika dan perilaku mahasiswa jurusan Akuntansi adalah jenis kelamin. Hasil studi oleh Ameen et al. (1996) menunjukkan bahwa, mahasiswi akuntansi lebih sensitif dan kurang toleran terhadap perilaku etis dan kurang sinisme. Perempuan memiliki perbedaan psikologis dengan laki-laki terutama faktor kepedulian yang akan menghasilkan tanggapan yang berbeda terhadap dilema etika. Perbedaan laki-laki dan perempuan tidak hanya dilihat dari sisi fisik dan biologis saja. Faktor kebudayaan, ilmu pengetahuan, adat istiadat, dan nilai sosial dapat mempengaruhi pembentukan perilaku setiap individu. Umumnya perempuan lebih mendahulukan perasaan dibandingkan laki-laki yang menggunakan logika dalam suatu kasus. Hal ini disebabkan karena perempuan lebih berhati-hati dalam mengambil suatu tindakan dan berusaha untuk menghindari risiko yang dapat merugikan dirinya dalam jangka panjang. Berbeda dengan laki-laki yang tidak terlalu memikirkan akibat jangka panjang dalam suatu pengambilan keputusan.

Berdasarkan penjelasan diatas, maka dirumuskan hipotesis berikut:

H1b: Kemampuan mahasiswa perempuan yang telah menerima pendidikan etika akuntansi lebih baik dalam mengidentifikasi dilema etika dibandingkan dengan kemampuan mahasiswa laki-laki 
Pertimbangan etis menggambarkan kemampuan untuk mengenali hal yang benar dilakukan secara moral. Beberapa penelitian menunjukkan bahwa pendidikan etika mampu meningkatkan kemampuan membuat pertimbangan etis mahasiswa. Muatan etika yang terdapat di berbagai mata kuliah akuntansi mengajarkan berbagai masalah etika yang akan dihadapi oleh mahasiswa dalam dunia kerja. Mahasiswa yang telah mengikuti pendidikan etika setidaknya akan memiliki kemampuan untuk menilai bahwa suatu tindakan adalah benar secara moral. Hal ini didasarkan pada materi yang ada di dalam muatan etika..

Berdasarkan penjelasan diatas, maka dirumuskan hipotesis berikut:

H2a: Kemampuan mahasiswa yang telah menerima pendidikan etika akuntansi lebih baik dalam membuat pertimbangan etis dibandingkan kemampuan mahasiswa yang belum mengikuti pendidikan etika akuntansi

Perempuan dianggap memiliki perilaku yang lebih etis dibandingkan laki-laki karena memiliki sikap peduli dan sikap sinisme yang kecil. Laki-laki dianggap lebih agresif dan bertindak berdasarkan logika. Perempuan yang telah mengikuti pendidikan etika dianggap mampu bertindak lebih etis karena kasus kecurangan dalam akademik lebih sering dilakukan oleh mahasiswa laki-laki. Mahasiswi juga memiliki pertimbangan yang berbeda dan tindakan yang berbeda dalam situasi moral. Sehingga mahasiswi akan lebih tinggi kemampuannya dalam menilai suatu tindakan benar secara moral dibandingkan laki-laki.

Berdasarkan penjelasan diatas, maka dirumuskan hipotesis berikut:

H2b: Kemampuan mahasiswa perempuan yang telah menerima pendidikan etika akuntansi lebih baik dalam membuat pertimbangan etis dibandingkan dengan kemampuan mahasiswa laki-laki

\section{METODE PENELITIAN}

\section{Metode Pengambilan Sampel}

Populasi dalam penelitian ini yaitu mahasiswa S1 Akuntansi di Universitas Bengkulu dari semester 2 hingga semester 8. Berdasarkan data dari pihak akademik, jumlah mahasiswa dari semester 2 hingga semester 8 adalah 483 orang. Jumlah mahasiswa untuk angkatan 2016 atau semester 2 yaitu 129 orang, angkatan 2015 atau semester 4 berjumlah 124 orang, angkatan 2014 atau semester 6 berjumlah 113 orang, dan angkatan 2013 atau semester 8 berjumlah 117 orang.

\section{Pengukuran dan Definisi Operasional Variabel}

\section{Pendidikan Etika Akuntansi}

Pendidikan etika akuntansi merupakan proses yang membantu mahasiswa untuk meningkatkan kemampuan dalam membuat keputusan etis sekaligus membantu mahasiswa untuk bertindak secara etis sebagai calon akuntan masa depan. Pendidikan etika akuntansi dapat diukur dengan tingkatan semester.

\section{Sensitivitas Etis}

Sensitivitas etis merupakan kesadaran seseorang untuk mengidentifikasi masalah moral serta sadar bahwa suatu tindakan akan mempengaruhi orang lain. Sensitivitas etis mahasiswa akuntansi akan diukur dalam skala likert 5 poin dengan menggunakan instrumen dengan 25 skenario yang didesain oleh Longenecker et al. (1989), Clark (1966), Fritzche \& Becker (1982), Harris (1991) yang dikembangkan dalam penelitian Conroy \& Emerson (2004). 


\section{Pertimbangan Etis}

Pertimbangan etis adalah kemampuan seseorang untuk mempertimbangkan apakah suatu tindakan etis yang akan diambil merupakan tindakan yang benar secara moral dan bagaimana pengaruhnya terhadap orang lain. Kuisioner yang digunakan merupakan instrumen dalam Accounting spesific-Defining Issuing Test (ADIT) yang dibuat oleh Thorne (2000) dalam (Thorne et al.,2004).

\section{Jenis Kelamin}

Jenis kelamin merupakan suatu akibat dari dimorfisme seksual yang pada manusia dikenal menjadi laki-laki dan perempuan. Sensitivitas etis dan pertimbangan etis mahasiswa akuntansi yang telah menerima pendidikan etika akuntansi akan diuji perbedaannya berdasarkan jenis kelamin. Jenis kelamin menggunakan skala nominal dimana angka 1 menunjukkan mahasiswa laki-laki dan angka 2 menunjukkan mahasiswa perempuan.

\section{Metode Analisis Data}

\section{Statistik Deskriptif}

Statistik deskriptif digunakan untuk menganalisis dan menyajikan sebagian besar data. Statistik deskriptif menampilkan nilai rata-rata (mean), ukuran penyebaran (standar deviasi), dan bentuk distribusi (nilai minimum dan maksimum) data.

\section{Uji Kualitas Data}

Pengujian validitas tiap butir pertanyaan dalam penelitian ini menggunakan metode Confirmatory Factor Analysis (CFA). Tingkat inkorelasi antar variabel dan dapat tidaknya dilakukan analisis faktor diukur dengan menggunakan Kaiser Meyer Olkin Measure of Sampling Adequency (KMO MSA) dan Barlett Test of Spericity, serta melihat skor factor loading $\geq 0,5$.

Kriteria yang digunakan dalam penelitian ini adalah One Shot, artinya satu kali pengukuran saja dan kemudian hasilnya dibandingkan dengan pertanyaan lainnya, pada SPSS reliabilitas dilakukan dengan uji statistik Cronbach Alpha (a). Suatu konstruk dikatakan realibel jika memberikan nilai $r>0,60$ (Nunally, 1981).

\section{Uji Normalitas Data}

Uji normalitas data menggunakan uji Normal Kolmogrov-Smirnov. Asumsi normalitas akan terpenuhi apabila jumlah sampel yang digunakan lebih dari atau sama dengan 30 maka dapat dikatakan normal. Pengujian normalitas data menggunakan uji One Sample Kolmogorov Smirnov Test, hasil pengujian akan menunjukkan tingkat signifikansi pada sig. (2-tailed). Apabila sig. (2-tailed) $<0,05$ disimpulkan bahwa data tidak terdistribusi secara normal.

\section{Uji Homogenitas}

Homogeneity of variance yaitu variabel dependen harus memiliki varian yang sama dalam setiap kategori variabel independen. Jika terdapat lebih dari satu variable independen, 
SENSITIVITAS ETIS DAN PERTIMBANGAN ETIS...

Anggi Ayu Septi K dan Lisa Martiah NP

maka harus ada homogeneity of variance di dalam cell yang dibentuk oleh variabel independen kategorikal. SPSS memberikan test ini dengan nama Levene's test of homogeneity of variance.

\section{Uji Hipotesis}

Di dalam analisis data penelitian digunakan metode statistika. Seluruh perhitungan statistik dilakukan dengan bantuan program statistik SPSS dengan analisis Independent Sample T-Test. Analisis Independent Sample T-Test bertujuan membandingkan rata-rata dari dua kelompok yang tidak berhubungan antara satu dengan yang lain, untuk mengetahui apakah kedua rata-rata tersebut mempunyai nilai yang sama atau tidak secara signifikan. Analisis Uji$\mathrm{t}$ digunakan dalam penelitian ini untuk mengetahui hipotesis pertama dan kedua. Pengujian melalui signifikan t-value adalah membandingkan signifikan t-value (t-hitung) dengan probabilitas $10 \%$. Penentuan hipotesis diterima atau ditolak dapat diketahui dengan melihat nilai t-value pada hasil analisis. Apabila sig T hitung > 0,05 maka Ho diterima, sedangkan jika Sig T hitung $<0,05$ maka Ho ditolak.

\section{HASIL PENELITIAN DAN PEMBAHASAN}

\section{Uji Validitas}

Untuk mengetahui valid suatu variabel, dilakukan pengujian dengan menggunakan teknik Confirmatory Factor Analysis di SPSS. Hasil pengujian validitas disajikan di Tabel :

\section{Tabel}

\section{Hasil Uji Validitas}

\begin{tabular}{|c|c|c|c|c|}
\hline Variabel & Kasus & Anti Image & $\begin{array}{c}\text { KMO and } \\
\text { Barlett Test }\end{array}$ & Keterangan \\
\hline \multirow[t]{8}{*}{ Sensitivitas Etis } & Kasus 1 & 0.680 & \multirow{8}{*}{$\begin{array}{c}0.680 \\
\text { Sig } 0.000\end{array}$} & Valid \\
\hline & Kasus 2 & 0.715 & & Valid \\
\hline & Kasus 3 & 0.692 & & Valid \\
\hline & Kasus 4 & 0.778 & & Valid \\
\hline & Kasus 5 & 0.649 & & Valid \\
\hline & Kasus 6 & 0.731 & & Valid \\
\hline & Kasus 7 & 0.639 & & Valid \\
\hline & Kasus 8 & 0.559 & & Valid \\
\hline \multirow[t]{3}{*}{ Pertimbangan Etis } & Tahap 5A & 0.677 & \multirow{3}{*}{$\begin{array}{c}0.674 \\
\text { Sig } 0.000\end{array}$} & Valid \\
\hline & Tahap 5B & 0.714 & & Valid \\
\hline & Tahap 6 & 0.643 & & Valid \\
\hline
\end{tabular}

Sumber: data primer yang diolah, 2017

\section{Uji Reliabilitas}

Untuk mengetahui apakah kuesioner untuk variabel sensitivitas etis reliabel atau handal maka dilakukan uji reliabilitas dengan uji statistik cronbach's alpha seperti pada Tabel : 
Tabel

Hasil Uji Reliabilitas

\begin{tabular}{c|c|c|c|c}
\hline Variabel & $\begin{array}{c}\text { Cronbach's } \\
\text { Alpha }\end{array}$ & $\begin{array}{c}\text { Cronbach's Alpha } \\
\text { Based on } \\
\text { Standardized Items }\end{array}$ & $\begin{array}{c}\text { N of } \\
\text { Items }\end{array}$ & Keterangan \\
\hline Sensitivitas Etis & 0.720 & 0.718 & 8 & Reliabel \\
\hline Pertimbangan Etis & 0.631 & 0.732 & 3 & Reliabel \\
\hline
\end{tabular}

Sumber: data primer yang diolah, 2017

\section{Uji Normalitas}

Untuk mendeteksi normalitas data digunakan uji Kolmogrov-Smirnov. Berikut hasil uji normalitas pada tabel :

Tabel 5

Uji Normalitas

\begin{tabular}{c|c|c|c|c}
\hline Variabel & $\mathbf{N}$ & $\begin{array}{c}\text { Kolmogrov- } \\
\text { Smirnov Z }\end{array}$ & $\begin{array}{c}\text { Asymp. Sig. } \\
\text { (2-tailed) }\end{array}$ & Keterangan \\
\hline Sensitivitas Etis & 83 & 1.141 & 0.148 & Normal \\
\hline Pertimbangan Etis & 83 & 1.496 & 0.018 & Tidak Normal \\
\hline
\end{tabular}

Sumber: data primer yang diolah, 2017

\section{Pengujian Hipotesis}

Uji hipotesis yang digunakan dalam penelitian ini menggunakan analisis independent sample t-test.

Tabel

Hasil Uji Hipotesis

Independent Sample T-Test

\begin{tabular}{c|c|c|c|c|c}
\hline Variabel & Dimensi & T & Df & $\begin{array}{c}\text { Sig. (2- } \\
\text { tailed) }\end{array}$ & Keterangan \\
\hline Sensitivitas Etis & Semester & 5.161 & 81 & 0.000 & $\begin{array}{c}\text { Hipotesis 1a } \\
\text { Diterima }\end{array}$ \\
\cline { 2 - 6 } & $\begin{array}{c}\text { Jenis } \\
\text { Kelamin }\end{array}$ & 1.574 & 38 & 0.124 & $\begin{array}{c}\text { Hipotesis 1b } \\
\text { ditolak }\end{array}$ \\
\hline Pertimbangan Etis & Semester & -5.529 & 81 & 0.000 & $\begin{array}{c}\text { Hipotesis 2a } \\
\text { diterima }\end{array}$ \\
\cline { 2 - 6 } & $\begin{array}{c}\text { Jenis } \\
\text { Kelamin }\end{array}$ & -2.281 & 38 & 0.028 & $\begin{array}{c}\text { Hipotesis 2b } \\
\text { diterima }\end{array}$ \\
\hline
\end{tabular}

Sumber: data primer yang diolah, 2017

\section{Pembahasan}

\section{Pengujian Hipotesis 1a}

Hipotesis 1 dalam penelitian ini menggunakan komponen pertama dalam model pengambilan keputusan etis yaitu sensitivitas etis. Berdasarkan penelitian ini, mahasiswa akuntansi mendapatkan dampak positif dari pendidikan etika akuntansi. Hal ini bisa dilihat dari 
hasil pengujian hipotesis 1a yang membandingkan sensitivitas etis mahasiswa akuntansi berdasarkan semester. Hasil dari hipotesis 1a menunjukkan bahwa terdapat perbedaan antara sensitivitas etis mahasiswa akuntansi berdasarkan tingkatan semester dengan nilai lebih tinggi pada mahasiswa semester 6 dan 8 (H1a diterima). Hasil ini membuktikan bahwa pendidikan etika yang diajarkan dalam program akuntansi memiliki dampak positif terhadap peningkatan kemampuan mahasiswa akuntansi dalam menyadari suatu masalah etika dengan asumsi semester 6 dan 8 lebih banyak menerima pendidikan etika akuntansi dibandingkan semester 2 dan 4. Hasil ini konsisten dengan penelitian Billiot et al (2012), Lau (2010), Cabe K (2013), Chan \& Leung (2006), LaGrone et al. (1996), Saat et al. (2010b), dan Tailor (2013), yang menyatakan bahwa pemberian pelatihan etika yang benar mampu meningkatkan sensitivitas etis mahasiswa akuntansi dan membuktikan bahwa mahasiswa yang telah mengikuti pendidikan etika lebih tinggi sensitivitas etisnya dibandingkan mahasiswa yang belum pernah mengikuti pelatihan etika.

\section{Pengujian Hipotesis $1 \mathrm{~b}$}

Hasil ini konsisten dengan penelitian Wang \& Calvano (2015) yang menyatakan bahwa tidak ada perbedaan secara signifikan antara laki-laki dan perempuan setelah mengikuti pendidikan etika. Hal ini bermakna bahwa pada saat ini wanita dan pria bisa saja sama-sama memiliki kekurangan dalam penalaran perilaku etis, banyak dari mereka yang bersaing di bidang karir, mencari kekuasaan, mencari kekayaan tanpa memikirkan pelanggaran etika di dalamnya. Keller et al. (2007) menegaskan bahwa tidak mendukung ide bahwa jenis kelamin berkaitan dengan perbedaan dalam pembuatan keputusan etis karena dengan meningkatkan partisipan perempuan dari program pendidikan akuntansi akan menyebabkan pada perspektif etika yang sama.

\section{Pengujian Hipotesis 2a}

Pengujian untuk Hipotesis 2a menunjukkan bahwa pertimbangan etis mahasiswa akuntansi pada kelompok semester 6 dan 8 lebih tinggi dibandingkan kemampuan membuat pertimbangan etis mahasiswa semester 2 dan 4 (hipotesis 2a diterima). Hal ini menunjukkan bahwa pendidikan etika akuntansi yang telah didapatkan oleh kelompok mahasiswa semester 6 dan 8 mampu menaikkan tingkat pertimbangan etis mahasiswa ketika dihadapkan dengan dilema etika.

\section{Pengujian Hipotesis 2b}

Hipotesis $1 \mathrm{~b}$ menguji tentang perbedaan pertimbangan etis antara mahasiswa laki-laki dan mahasiswa perempuan setelah mengikuti pendidikan etika dan terbukti bahwa terdapat perbedaan antara kemampuan membuat pertimbangan etis antara mahasiswa laki-laki dan mahasiswa perempuan dengan nilai lebih tinggi pada mahasiswa perempuan. Hasil ini konsisten dengan studi dari Abdolmohammadi \& Reeves (2000), Barac (2005), Borkowski \& Ugras (1992), Gammie (2009), dan Lau (2010) yang menyatakan bahwa mahasiswa perempuan cenderung memiliki pertimbangan moral yang lebih tinggi dibandingkan mahasiswa laki-laki. Lau (2010) menyatakan bahwa mahasiswi cenderung memiliki kesadaran etika dan penalaran moral yang tinggi karena mahasiswi lebih kecil kemungkinannya untuk membayar suap dan menghasilkan tekanan. Penelitian dari Gammie (2009) dan Barac (2005) juga menyatakan bahwa mahasiswa perempuan lebih cenderung berperilaku etis dibandingkan mahasiswa lakilaki dan terbukti bahwa mahasiswa laki-laki lebih sering berperilaku tidak etis dalam setting akademik. 


\section{PENUTUP}

\section{Simpulan}

Penelitian ini bertujuan untuk mengetahui apakah terdapat perbedaan sensitivitas etis dan pertimbangan etis mahasiswa akuntansi berdasarkan tingkat semester dan jenis kelamin. Berdasarkan hasil analisis data diperoleh data bahwa kemampuan mahasiswa akuntansi yang telah mengikuti pendidikan etika akuntansi lebih tinggi dalam mengidentifikasi masalah etis (sensitivitas etis) dibandingkan kemampuan mahasiswa yang belum mengikuti pendidikan etika akuntansi. Namun berdasarkan jenis kelamin, tidak terdapat perbedaan antara kemampuan mahasiswa laki-laki dan mahasiswa perempuan dalam mengidentifikasi masalah etis (sensitivitas etis) setelah mengikuti pendidikan etika. Dalam hal pertimbangan etis, kemampuan mahasiswa yang telah mengikuti pendidikan etika lebih baik dalam membuat pertimbangan etis dibandingkan kemampuan mahasiswa yang belum mengikuti pendidikan etika. Sedangkan perbedaan kemampuan berdasarkan jenis kelamin, kemampuan mahasiswa perempuan yang telah mengikuti pendidikan etika akuntansi lebih baik dalam membuat pertimbangan etis dibandingkan kemampuan mahasiswa laki-laki.

\section{IMPLIKASI DAN KETERBATASAN}

Terlepas dari beberapa keterbatasan, penelitian ini memiliki beberapa implikasi yaitu Sensitivitas etis merupakan kemampuan awal yang diperlukan bagi individu dalam proses pembuatan keputusan etis. Sensitivitas etis merupakan salah satu faktor individu yang dimiliki oleh mahasiswa Akuntansi untuk membentuk persepsi yang benar atas kejadian yang ada, sehingga dapat menarik kesimpulan bahwa kejadian tersebut etis atau tidak. Hal ini mengandung implikasi agar kedepannya mahasiswa Akuntansi lebih meningkatkan sensitivitas etis yang dimiliki, sehingga mereka bisa lebih peka terhadap perilaku yang menyimpang dari etika.

Pada lembaga pendidikan khususnya universitas harus mengetahui cara meningkatkan sensitivitas etis mahasiswa perempuan dan mahasiswa laki-laki. Hal itu bisa diperbaiki dengan penambahan kasus etika ke dalam mata kuliah sehingga mahasiswa mengetahui berbagai isu etika di bidang akuntansi.

Penelitian ini memiliki keterbatasan yaitu hanya meneliti 2 dari 4 komponen model pengambilan keputusan etis oleh Rest yaitu sensitivitas etis dan pertimbangan etis. Hal ini dikarenakan kurangnya penelitian mengenai komponen ketiga yaitu motivasi moral yang membuat peneliti sulit untuk melakukan pengembangan penelitian. Sedangkan komponen keempat merupakan tindakan moral yang sulit untuk dilakukan pengukurannya karena tindakan moral merupakan tahap akhir dari proses pengambilan keputusan etis yang berupa tindakan hingga menjadi perilaku.

Hasil penelitian ini memberikan masukan bagi pihak-pihak yang berkepentingan yaitu untuk penelitian selanjutnya agar memperluas sampel tidak hanya mahasiswa univesitas negeri namun menambahkan dengan universitas swasta. Selain itu, untuk penelitian selanjutnya agar memperluas penelitian dengan memasukkan komponen lain dari proses pengambilan keputusan etis oleh Rest seperti motivasi moral. Disarankan untuk penelitian selanjutnya agar memberikan kuesioner dengan kasus yang sesuai dengan situasi dan kebudayaan di Indonesia agar mudah dipahami oleh responden. 


\section{DAFTAR PUSTAKA}

Abdolmohammadi, M. J., \& Reeves, M. F. (2000). Effects Of Education And Intervention On Business Students' Ethical Cognition: A Cross Sectional And Longitudinal Study. Teaching Business Ethics, 269-284.

Alteer, A. M., Yahya, S. B., \& Haron, M. H. (2013). The Mediating Impact of Ethical Orientation on the Religiosity and Undergraduate Auditing Students' Ethical Sensitivity Relationship. International Journal of Finance and Accounting, 2(8), 472-477.

Ameen, E. C., Guffey, D. M., \& McMillan, J. J. (1996). Gender Differences in Determining the Ethical Sensitivity of Future Accounting Professionals. Journal of Business Ethics , 15, 591-597.

Arfaoui, F., Ayadi, S. D., Ghram, R., \& Bouchekoua, A. (2016). Ethics Education and Accounting Students' Level of Moral Development: Experimental Design in Tunisian Audit Context. Journal Bussiness Ethics, 161-173.

Armstrong, M. B. (1993). Ethics and professionalism in accounting education: a sample course. Journal of Accounting Education, 11, 11-92.

Barac, E. S. (2005). A study of the ethical views of final year South African accounting students, using vignettes as examples. Meditari Accountancy Research, 13(2), 107 - 128.

Bebea, D. Y. (2013). The independence of James Rest's components of morality: evidence from a professional ethics curriculum study. Ethics and Education, 8(3), 202-216.

Bennie, N. M., \& Mladenovic, R. (2013). Investigation of the impact of an ethical framework and an integrated ethics education on accounting students' ethical sensitivity and judgment. Journal of Business Ethics, 189-203.

Billiot, M. J., Daniel, D., Glandon, S., \& Glandon, T. (2012). Educational Context: Preparing Accounting Students To Identify Ethical Dilemmas. American Journal Of Business Education - May/June 2012, 5, 277-286.

Borkowski, S. C., \& Ugras, Y. J. (1992). The Ethical Attitudes of Students as a Function of Age, Sex and Experience. Journal of Business Ethics, 11, 961-979.

Burns, D. J., Tackett, J. A., \& Wolf, F. (2015). The effectiveness of instruction in accounting ethics education: another look. Research on Professional Responsibility and Ethics in Accounting, 19, 149-180.

Cabe, K. (2016, January). The Effect of Attending an Accounting Ethics Course on Students' Ethical Sensitivity. Prescott Valley, Arizona: ProQuest LLC.

Chan, S. Y., \& Leung, P. (2006). The effects of accounting students' ethical reasoning and personal factors on their ethical sensitivity". Managerial Auditing Journal, 21(4), 436457.

Chocolate, C. P. (2013). The effect of ethics education on the development of ethical sensitivity of undergraduate accounting students: an exploratory study in angola.

Conroy, S. J., \& Emerson, T. L. (2004). Business Ethics and Religion: Religiosity as a Predictor of Ethical Awareness among Students. Journal of Business Ethics, 50, 383-396.

Cooper, B. J., Leung, P., Dellaportas, D., Jackling, B., \& Wong, G. (2008). Ethics education for accounting students: A toolkit approach. Accounting Education: An International Journal, 17(4), 405-430.

Dellaportas, S. (2006). Making a difference with a discrete course on accounting ethics. Journal of Business Ethics, 65, 391-404.

Earley, C. E., \& Kelly, P. T. (2004). A note on ethics educational interventions in an undergraduate auditing course: Is there an 'Enron Effect". Issues in Accounting Education, 19(1), 53-71.

Gammie, E. G. (2009). The moral awareness of future accounting and business professionals: The implications of a gender divide. Pacific Accounting Review, 21(1), 48-73. 
Ghazali, N. A. (2015). The influence of a business ethics course on ethical judgments of Malaysian accountants. Journal of Asia Business Studies, 9(2), 147-161.

Ghozali, I. (2011). Aplikasi Analisis Multivariate dengan Program SPSS (Vol. 5). Semarang: Badan Penerbit Universitas Dipenogoro.https://id.m.wikipedia.org

Ho, Y.-H. (2007). Undergraduate Accounting Students' Perceptions Of Accounting Ethics: A Cross-Cultural Comparative Study. United states: ProQuest Information and Learning Company.

Hutahahean, M. U., \& Hasnawati. (2015). Pengaruh Gender, Religiusitas Dan Prestasi Belajar Terhadap Perilaku Etis Akuntan Masa Depan (Studi Pada Mahasiswa Akuntansi Perguruan Tinggi Swasta di Wilayah DKI Jakarta). e-Journal Akuntansi Trisakti, 2(1), 49-66.

Jagger, S. (2011). Ethical sensitivity: a foundation for moral judgment. Journal of Business Ethics Education, 8, 13-30.

Keller, A. C., Smith, K. T., \& Smith, L. M. (2007). Do gender, educational level, religiosity, and work experience affect the ethical decision-making of U.S. accountants? Critical Perspectives on Accounting, 18, 299-314.

LaGrone, R. M., Welton, R. E., \& Davis, J. R. (1996). Are The Effects Of Accounting Ethics Interventions Transitory Or Persistent? Journal of Accounting Education, 14(3), 259276 ,

Lau, C. L. (2010). A Step Forward: Ethics Education Matters! Journal of Business Ethics(92), $565-584$.

Leitsch, D. L. (2006, June ). Using dimensions of moral Intensity. Accounting Education: an international journal, 15(2), 135-149.

Lubis, A. I. (2010). Akuntansi keperilakuan. Jakarta: Salemba Empat.

Lung, C. K., \& Chai, L. T. (2010, May). Attitude towards Business Ethics: Examining the Influence of Religiosity, Gender and Education Levels. International Journal of Marketing Studies, 2(1), 225-232.

Molyneaux, D. (2004). After Andersen: An experience of integrating ethics into undergraduate accountancy education. Journal of Business Ethics, 54(4), 385-398.

Mugan, C. S., \& Atay, D. O. (2003). Contextual effects on ethical sensitivity and penalty judgments. Teaching Business Ethics, 341-363.

O'Leary, C. (2009, September-December). An empirical analysis of the positive impact of ethics teaching on accounting students. Accounting Education: an international journal, 18(4-5), 505-520.

Onumah, J. M., Gyamfi, N. Y., Djin, M., \& Adomako, D. (2012). Education in a developing country: exploratory evidence from the premier university in ghana. Accounting in Emerging Economies, 12A, 127-154.

Saat, M. M., Porter, S., \& Woodbine, G. (2009). Does Religiosity Influence Ethical Sensitivity? An Investigation On Malaysian Future Accountants. Malaysian Accounting Review, $8(2), 17-42$.

Saat, M. M., Porter, S., \& Woodbine, G. (2010). An Exploratory Study of the Impact of Malaysian Ethics Education on Ethical Sensitivity. Journal of Business Ethics Educati, 7, 39-62.

Saat, M. M., Porter, S., \& Woodbine, G. (2010). The effect of ethics courses on the ethical judgement-making ability of Malaysian accounting students. Journal of Financial Reporting and Accounting, 8(2), 92-109.

Saat, M. M., Porter, S., \& Woodbine, G. (2012, December 12). A longitudinal study of accounting students' ethical judgement making ability. Accounting Education: An International Journal, 21(3), 215-229. 
SENSITIVITAS ETIS DAN PERTIMBANGAN ETIS...

Anggi Ayu Septi K dan Lisa Martiah NP

Sapariyah, R. A., Setyorini, P., \& Dharma, A. B. (2015). Pengaruh Muatan Etika Dalam Pengajaran Akuntansi Keuangan, Kecerdasan Intelektual, Kecerdasan Emosional, dan Kecerdasan Spiritual Terhadap Sikap Etis Mahasiswa Akuntansi. Jurnal Paradigma, 13(2), 1-15.

Sari, L. P. (2012). Pengaruh Muatan Etika dalam Pendidikan Akuntansi terhadap Persepsi Etika Mahasiswa. Jurnal Akuntansi Multiparadigma, 3(3), 334-501.

Shawver, T. J., \& Shawver, T. A. (2013). Accounting students ethical sensitivity and moral judgments for business dilemmas. Research on Professional Responsibility and Ethics in Accounting, 17, 159-176.

Shawver, T. J., \& Shawver, T. A. (2014). Accounting Students' Ethical Sensitivity and Moral Judgments for Business Dilemmas. Research on Professional Responsibility and Ethics , 159-176.

Siswanto, V. A. (2015). Belajar Sendiri SPSS. Yogyakarta: CV. ANDI OFFSET.

Taylor, A. (2013). Ethics training for accountants: does it add up? Meditari Accountancy Research, 21(2), 161 - 177.

Thorne, L. (2001). Refocusing ethics education in accounting: an examination of accounting students' tendency to use their cognitive moral capability. Journal of Accounting Education, 19, 103-117.

Thorne, L., Massey, D. W., \& Jones, J. (2004). An Investigation Of Social Influence: Explaining The Effect Of Group Discussion On Consensus In Auditors' Ethical Reasoning. Business Ethics Quarterly, 14(3), 525-551.

Utami, W., \& Indriawati, F. (2006). Muatan Etika Dalam Pengajaran Akuntansi Keuangan Dan Dampaknya Terhadap Persepsi Etika Mahasiswa: Studi Eksperimen Semu. SIMPOSIUM NASIONAL AKUNTANSI, (hal. 1-29). Padang.

Vega, J. (1986). Diambil kembali dari https://www.scribd.com/: https://www.scribd.com/doc/60211824

Wang, L. C., \& Calvano, L. ((2015)). Is Business Ethics Education Effective? An Analysis of Gender, Personal Ethical Perspectives, and Moral Judgment. Journal Business Ethics, 126, 591-602. 